\title{
Current advances in biomarkers for targeted therapy in triple-negative breast cancer
}

This article was published in the following Dove Press journal:

Breast Cancer - Targets and Therapy

6 October 2016

Number of times this article has been viewed

\author{
Brett Fleisher \\ Charlotte Clarke ${ }^{2}$ \\ Sihem Ait-Oudhia' \\ 'Department of Pharmaceutics, \\ Center for Pharmacometrics and \\ Systems Pharmacology, College of \\ Pharmacy, University of Florida, \\ Orlando, FL, ${ }^{2}$ Department of \\ Translational Research, UT \\ MD Anderson Cancer Center, \\ Houston, TX, USA
}

Correspondence: Sihem Ait-Oudhia Department of Pharmaceutics, Center for Pharmacometrics and Systems Pharmacology, College of Pharmacy, University of Florida, 6550 Sanger Road, Room 469, Orlando, FL 32827, USA

$\mathrm{Tel}+\mathrm{I} 4073137037$

Fax + I 4073137030

Email sihem.bihorel@cop.ufl.edu
Abstract: Triple-negative breast cancer (TNBC) is a complex heterogeneous disease characterized by the absence of three hallmark receptors: human epidermal growth factor receptor 2, estrogen receptor, and progesterone receptor. Compared to other breast cancer subtypes, TNBC is more aggressive, has a higher prevalence in African-Americans, and more frequently affects younger patients. Currently, TNBC lacks clinically accepted targets for tailored therapy, warranting the need for candidate biomarkers. BiomarkerBase, an online platform used to find biomarkers reported in clinical trials, was utilized to screen all potential biomarkers for TNBC and select only the ones registered in completed TNBC trials through clinicaltrials.gov. The selected candidate biomarkers were classified as surrogate, prognostic, predictive, or pharmacodynamic (PD) and organized by location in the blood, on the cell surface, in the cytoplasm, or in the nucleus. Blood biomarkers include vascular endothelial growth factor/vascular endothelial growth factor receptor and interleukin-8 (IL-8); cell surface biomarkers include EGFR, insulin-like growth factor binding protein, c-Kit, c-Met, and PD-L1; cytoplasm biomarkers include PIK3CA, pAKT/S6/p4E-BP1, PTEN, ALDH1, and the PIK3CA/AKT/mTOR-related metabolites; and nucleus biomarkers include $B R C A 1$, the glucocorticoid receptor, TP53, and Ki67. Candidate biomarkers were further organized into a "cellular protein network" that demonstrates potential connectivity. This review provides an inventory and reference point for promising biomarkers for breakthrough targeted therapies in TNBC.

Keywords: anti-cancer directed pharmacotherapy, difficult-to-treat breast cancer, biological markers

\section{Introduction}

Breast cancer is the most common cancer in women, and the second most frequent cause of cancer-related deaths in women worldwide. ${ }^{1}$ Approximately $20 \%$ of all breast cancers are referred to as triple-negative breast cancer (TNBC) due to a lack of three proteins: estrogen receptor (ER), progesterone receptor (PR), and human epidermal growth factor receptor 2 (HER2). ${ }^{2}$ TNBC tends to be more aggressive than other breast cancer subtypes and has a higher prevalence in African-Americans, more frequently affects younger patients (average age $<50$ years), and is associated with a greater risk of mortality. ${ }^{1,3}$ Currently, breast cancer treatment options and outcome are highly dependent on targeting ER, PR, or HER2. As a result, the American Society of Clinical Oncology (ASCO) does not currently recommend tailoring therapy for TNBC but instead recommends a general chemotherapy treatment based on the combination of an anthracycline with a taxane. ${ }^{4}$ 
Although physicians have found that TNBC will initially respond to the combination of anthracycline and taxanes, treatment failure and disease recurrence continue to be clinically challenging. ${ }^{5}$ Clinicians have attempted to tailor therapy for TNBC by monitoring the Food and Drug Administration (FDA)-approved biomarkers which can be classified as surrogate, prognostic, predictive, or pharmacodynamic (PD). ${ }^{6}$ Surrogate biomarkers may predict an outcome by acting as a substitute for a clinical endpoint. ${ }^{7}$ For example, evidence suggests that interleukin-8 (IL-8) blood levels are linked to breast cancer resistance protein (BCRP), a transient efflux transporter ${ }^{8}$ that confers resistance to cytotoxic drugs $; 9$ therefore, IL- 8 could be measured as a surrogate biomarker for BCRP levels in TNBC. Prognostic biomarkers suggest survival probability for cancer patients with and without drug therapy and would be used to ascertain whether patients require additional therapy. ${ }^{6}$ For example, one study found that the presence of $\mathrm{c}-\mathrm{Kit}$, a protein expressed during cell replication, may determine the progression of TNBC. ${ }^{10}$ Predictive biomarkers (also known as companion biomarkers) identify subpopulations of patients who are most likely to benefit from a specific drug therapy and form the basis for tailored-TNBC therapies. The HER2 protein is an example of a predictive biomarker that indicates a breast cancer that is more likely to have a favorable response to the drug trastuzumab (Herceptin; Genetech, Inc., South San Francisco, CA, USA) ${ }^{4}$ Finally, PD biomarkers assess which molecular indicators are linked to a drug regimen, target effect, or tumor response, thereby providing rationale for new drug targets, drug combinations, or assay development. S6 and P4E-BP1 are potential PD biomarkers as their expression in in vitro TNBC experiments reflects activity in the TNBC chemotherapy-resistance pathway, PIK3CA/AKT/mTOR. ${ }^{11}$

Although these four types of biomarkers provide a cornerstone of modern cancer therapeutics, they have not demonstrated significant clinical utility in the treatment of TNBC, ${ }^{4}$ likely due to its highly complex biology and interpatient heterogeneity. ${ }^{4}$ TNBC often exhibits resistance to standard combination chemotherapy through multiple interacting pathways with feedback and cross-talk loops. ${ }^{6}$ These loops, in turn, may be altered by mutations in coding regions, regulatory elements, and noncoding sequences in the tumor DNA and gene expression, ${ }^{12}$ which leads to downstream protein-protein, protein-gene, and other interactions which cannot be represented by single protein biomarker.

In the last decade, -omics technologies have been used to analyze the complex biology of TNBC by examining several forms of macromolecules (eg, DNA, RNA, proteins, and car- bohydrates) that may shed light on TNBC signaling pathways. ${ }^{13}$ These-omics technologies include proteomics, metabolomics, genomics, and epigenomics. Proteomic studies are used to measure the changes in tumor-associated proteins, which can differentiate between samples of normal tissue, benign, and malignant tumor or as any of the biomarkers described above. For example, the modification of specific proteins in patients with TNBC differentiates TNBC pathology and physiology from that of other forms of breast cancer. ${ }^{14}$ In metabolomics, one analyzes how cells utilize small molecules (lipids, small peptides, and vitamins) to meet the energy requirements for sustaining life, and as building blocks for cellular division. For example, unlike healthy tissue, tumors perform aerobic glycolysis, thereby increasing lactate concentrations, which is known as the Warburg effect. In TNBC, this process appears to be interconnected with tumorigenic pathways $\mathrm{PI} 3 \mathrm{~K} / \mathrm{mTOR}^{15}$ and EGFR, ${ }^{16,17}$ and metabolomic assays may be used to measure the response of TNBC to specific therapies that target these pathways. ${ }^{13}$ Genomic studies of cancer cells examine genes specific to the tumor pathology which can include gene copy number, single nucleotide polymorphisms (SNPs), mutations, and loss of heterogeneity. ${ }^{12}$ For example, deleterious BRCA1 mutations are found in high-risk TNBC population ${ }^{18-20}$ and may increase tumor susceptibility to DNA-damaging and PARP inhibitor therapies. ${ }^{21}$ Epigenomics is the examination of changes in cell phenotype that are the result of gene modification, such as DNA methylation, rather than changes in the DNA sequence itself. ${ }^{22}$ For example, a significant proportion of TNBC may have BRCA1 promotor site hypermethylation; ${ }^{18,23,24}$ although epigenetic silencing creates a similar protein profile to the loss-of-function $B R C A 1$ mutation, ${ }^{25}$ therapeutic efficacy may differ. ${ }^{26}$

Aside from the complexity of TNBC, finding new and improved TNBC biomarkers is logistically challenging for several reasons. Centralized tumor specimen banks require proper sample collection, processing, and storage, which add financial burden ${ }^{27}$ and may deter candidate institutions from investing the necessary start-up capital. Following sample collection, data mining for novel biomarkers is time consuming and requires substantial input from data managers, bioinformaticians, and biostatisticians to correctly interpret the results. ${ }^{6}$ Additionally, the biomarker discovery process is not always straightforward. ${ }^{28}$ For example, because most cancer treatments use combination therapy rather than monotherapy, it can be difficult to connect the identified biomarker to a single drug or target. ${ }^{6}$ Before a new biomarker can be implemented in the clinic, newly discovered TNBC biomarkers must be thoroughly examined and validated in order to 
potentially fill the gaps in our understanding of TNBC treatment and patient survival. In this work, biomarkers that have been studied in late-stage clinical trials were reviewed and were classified according to its biological location as blood (plasma or serum), cell surface, cytoplasm, or nucleus biomarkers. How recently published -omics studies may provide useful information on TNBC biomarkers is also discussed, and these markers are connected through an evidence-based molecular pathway landscape.

\section{Methodology of data mining for biomarkers in TNBC}

There are many preclinical study publications on TNBC biomarkers; a recent search in PubMed Central using the words "triple negative breast cancer and biomarker" returned over 2300 search results. In order to select only biomarkers with the most clinician-backed support, biomarkers associated with completed TNBC trials were chosen to be focused on by using BiomarkerBase, a biomarker knowledgebase ${ }^{\mathrm{TM}}$ developed by Amplion. BiomarkerBase uses a comprehensive list of synonyms to identify biomarkers registered in the records of clinical trials via the government website clinicaltrials.gov.

With BiomarkerBase, breast cancer biomarkers were first found through the search engine. Then, for each breast cancer biomarker, subsearches were conducted for clinical trials that explicitly used TNBC (or the full name, triple-negative breast cancer) in the title of the study. If the breast cancer biomarker was registered in at least one completed TNBC study, the biomarker was analyzed (with the exceptions of HER2, ER, and PR). Of note, most clinical trials surveyed for the work presented in this review completed Phase II or III. Current literature about the biomarkers was further examined using PubMed. Papers that studied one of the biomarkers as a general-disease biomarker, explored how -omics studies further characterized these biomarkers, and examined how the biomarker pathways may interact were sought.

\section{Current advances in clinical biomarkers for TNBC patients}

The following sections examine biomarkers found in the blood, on the cell surface, in the cytoplasm or nucleus in TNBC samples. Circulating blood biomarkers include vascular endothelial growth factor (VEGF), its receptor, VEGFR, and interleukin-8 (IL-8). The cell surface receptors include endothelial growth factor receptor (EGFR), insulin-like growth factor binding proteins (IGFBP), c-Kit, and PD-L1. All the plasma and cell surface biomarkers used in this review are associated with completed-TNBC clinical trials. Cytoplasm biomarkers include PIK3CA, pAKT/S6/ p4E-BP1, PTEN, and PIK3CA/AKT/mTOR metabolites, in addition to ALDH1. PIK3CA, PTEN, ALDH1, and p4EBP1 were registered in completed TNBC clinical trials, whereas $\mathrm{pAKT} / \mathrm{S} 6$ biomarkers and the PIK3CA/AKT/mTOR metabolites were not. Nuclear biomarkers include $B R C A 1$, the glucocorticoid receptor (GR), TP53, and Ki67 and were all studied in completed TNBC trials.

Figure 1 shows the system biology of TNBC. It summarizes all identified biomarkers through a "cellular protein network" that demonstrates the potential connectivity between the different subtypes of biomarkers. Table 1 provides an overview of the examined surrogate, prognostic, predictive, and PD biomarkers in TNBC in addition to current literature found in PubMed that provides support for their potential use.

\section{TNBC biomarkers in blood}

Tumors or neighboring cells have been shown to release proteins that influence the survival of tumor cells, ${ }^{3,29}$ thereby leading to a worse outcome in TNBC patients. Only few biomarkers were reported in the serum or plasma of TNBC patients in late-stage clinical trial, and so far, none has been approved by the FDA, yet. They include VEGF, VEGFR, and IL-8.

\section{VEGF/VEGFR}

VEGF is typically found in blood as a disulfide-linked homodimer. Created from a family of six proteins, these VEGF isoforms include VEGF-A, VEGF-B, VEGF-C, VEGF-D, VEGF-E, and placental growth factor (PlGF). Glycosylated VEGF binds the VEGFR, a family of receptor tyrosine kinases (RTKs) including VEGFR1, VEGFR2, and VEGFR3, which upon stimulation lead to an increase of angiogenesis and the permeability of nearby vessels and lymphatics, ${ }^{3,30,31}$ the end result of which is improved oxygen/nutrient transport, as well as increased tumor metastasis. ${ }^{32,33}$

Roberti et $\mathrm{a} \mathrm{l}^{34}$ demonstrated the potential use for VEGF as a prognostic biomarker in TNBC. Briefly, animal models were implanted with either metastatic or nonmetastatic TNBC cells. The metastatic TNBC cells tended to express higher levels of PIGF and VEGF-A than the nonmetastatic counterparts, suggesting that overexpression of these markers correlated with metastatic potential for TNBC. Later, in a clinical study conducted by Bahhnassy et al, ${ }^{35}$ VEGF-A expression was examined before and after standard chemotherapy. In agreement with Roberti's study, the expression of VEGF-A correlated with a poorer overall survival and a less-favorable response to chemotherapy. 


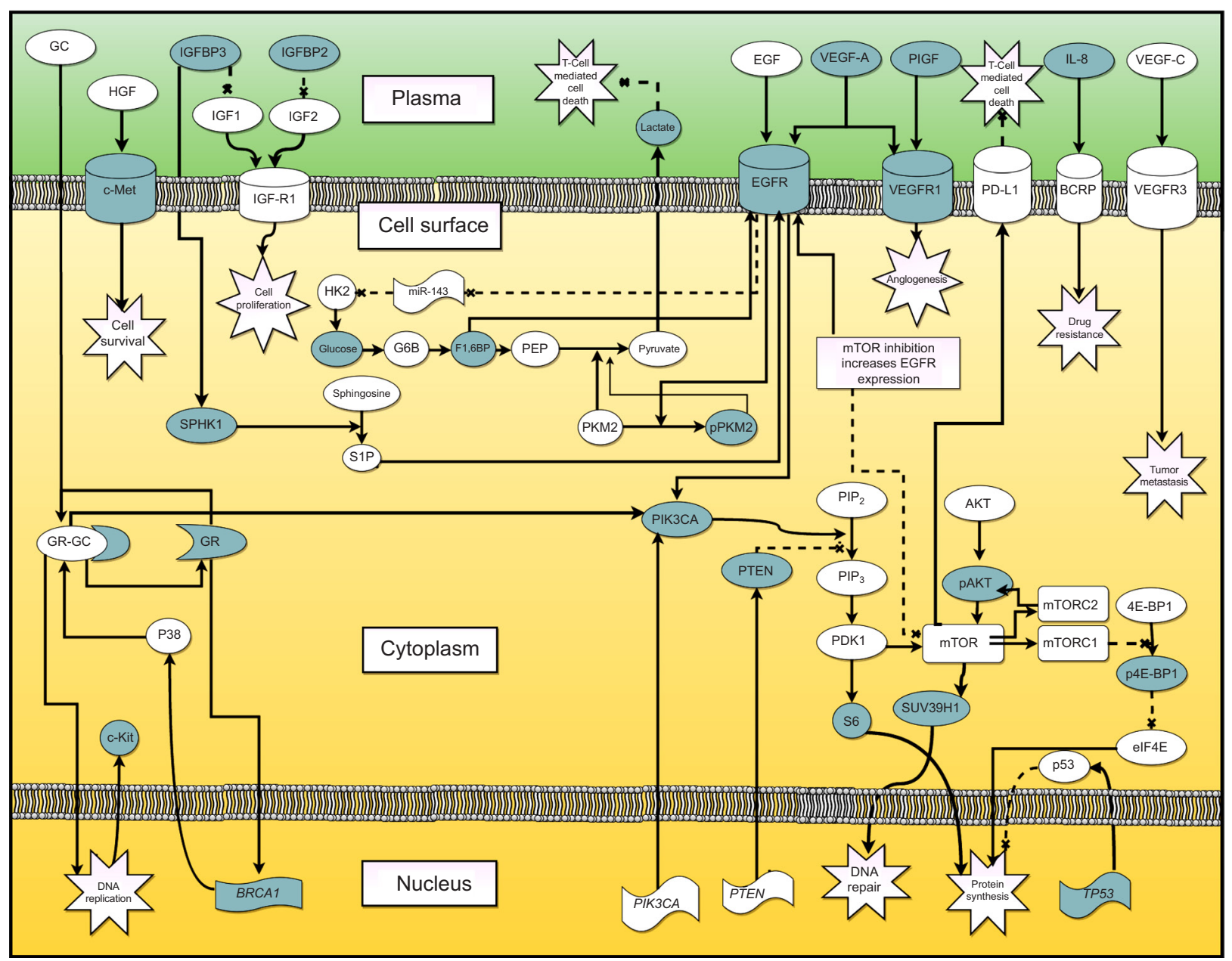

Figure I Biomarker pathways summarized through a "cellular protein network" that demonstrates potential connectivity.

Notes: BiomarkerBase, a biomarker knowledgebase ${ }^{\mathrm{TM}}$ developed by Amplion, was used to find registered biomarkers in completed TNBC trials through clinicaltrials. gov with the exception of HER2 and ER/PR. Current literature about the biomarkers was located using PubMed. The protein map is sectioned into plasma (blood), cell surface, cytoplasm, and nucleus. Biomarkers shown in cylinders represent markers found on the cell surface, rounded-edged boxes and circles represent other proteins or metabolites, and curved boxes represent DNA or RNA. Biomarkers examined more thoroughly throughout the review are filled in with gray. A black line with an arrow represents increase, expression, or activation; a dotted lined connected to an $\mathrm{X}$ represents inhibition. Star figures denote action such as tumor suppression and cell proliferation.

Abbreviations: EGF, endothelial growth factor; ER, estrogen receptor; GC, glucocorticoid; GR, glucocorticoid receptor; HER2, human epidermal growth factor receptor 2; HGF, hepatocyte growth factor; HK2, hexokinase 2; IGFBP, insulin-like growth factor binding protein; IGF-RI, IGF receptor I; IL-8, interleukin-8; mTOR, mammalian target of rapamycin; PDKI, phosphoinositide-dependent kinase I; PIP, phosphatidylinositol 4,5-biphosphate; PIP , phosphatidylinositol 3,4,5-triphosphate; PKM2, Pyruvate kinase M2; PPKM2, phosphorylated version of pyruvate kinase M2; PR, progesterone receptor; SPHKI, sphingosine kinase I; VEGF, vascular endothelial growth factor; BCRP, breast cancer resistance protein.

Overwhelming preclinical evidence predicted a positive response to bevacizumab (anti-VEGFA therapy) in TNBC patients, and thus, the potential for VEGF as a predictive biomarker for VEGF-tailored treatment; ${ }^{36,37}$ unfortunately, the clinical results were not positive. Bear et al ${ }^{38}$ examined breast cancer response to the combination of bevacizumab and standard chemotherapy. The addition of bevacizumab significantly increased the overall rate of pathological complete response (pCR), but after subset analysis, bevacizumab was found to be slightly more effective in the HER2-positive group than the TNBC group.

Shortly after Bear et al released their results, Chen et $\mathrm{al}^{21}$ released a meta-analysis examining eleven studies focused on standard neoadjuvant chemotherapy with- and without bevacizumab in TNBC patients. The meta-analysis revealed that, overall, TNBC treated with bevacizumab resulted in an improvement in pCR. ${ }^{21}$ Interestingly, Chen et al found no clear homogeneity between the studies, suggesting that the current studies do not provide enough patient details including VEGF-A expression to determine which TNBC subgroups most benefit from VEGF therapy.

VEGFR levels may be indicative of successful antiVEGF-A therapy in TNBC. Recently, Tolaney et al ${ }^{39}$ conducted a Phase II study to examine the effect of bevacizumab on TNBC patients and found that TNBC with high VEGFR1 
Table I Potential triple-negative breast cancer biomarkers

\begin{tabular}{|c|c|c|c|c|}
\hline Biomarkers & $\begin{array}{l}\text { Surrogate } \\
\text { biomarker }\end{array}$ & $\begin{array}{l}\text { Prognostic } \\
\text { biomarker }\end{array}$ & $\begin{array}{l}\text { Predictive } \\
\text { biomarker }\end{array}$ & $\begin{array}{l}\text { PD } \\
\text { biomarker }\end{array}$ \\
\hline VEGF, VEGFR & & 3,34 & 39 & 3 \\
\hline IL-8 & 9 & & & \\
\hline EGFR & & 49,50 & & \\
\hline pPKM2 & & & & 17 \\
\hline $\mathrm{FI}, 6 \mathrm{BP}$ & & & & 17 \\
\hline Lactate/ glucose & & & & 15,17 \\
\hline IGFBP2 & & 34,60 & & \\
\hline IGFBP3 & & 55 & & \\
\hline SPHKI & & & & 62,63 \\
\hline c-Kit & & $10,66,67$ & & \\
\hline c-Met & & 132 & & \\
\hline PD-LI & & & 79 & \\
\hline STATI/IRF2BP2 & 75 & & & \\
\hline S6 & & & 79 & 11 \\
\hline P4E-BPI & & $91-93$ & & 11 \\
\hline SUV39HI & & & & 11,95 \\
\hline PTEN & 133 & & 60 & \\
\hline GPC, PCh & & $|5,10|$ & & \\
\hline ALDHI & 106 & $84,104,105$ & & \\
\hline BRCAI mutations & & & 21 & \\
\hline BRCAI promotor & & & 26,122 & \\
\hline \multicolumn{5}{|l|}{ hypermethylation } \\
\hline GR & & & & $124-128$ \\
\hline TP53 & & $45,85,122,130$ & & \\
\hline
\end{tabular}

Notes: An overview of the examined surrogate, prognostic, predictive, or PD TNBC biomarkers in addition to current literature found in PubMed that provides support for their potential use.

Abbreviations: EGFR, endothelial growth factor receptor; GPC, glycerophosphocholine; GR, glucocorticoid receptor; IGFBP, insulin-like growth factor binding protein; IL-8, interleukin-8; PPKM2, phosphorylated version of pyruvate kinase M2; SPHKI, sphingosine kinase I; VEGF, vascular endothelial growth factor; VEGFR, vascular endothelial growth factor receptor.

had the greatest response to anti-VEGF-A therapy. The therapy appeared to prune vessels high in VEGFR1 while normalizing the other vessels, suggesting that high baseline VEGFR1 microvascular density may be required for successful neoadjuvant anti-VEGF-A therapy in TNBC. TNBC may be dependent on both VEGF and VEGFR analysis for effective treatment, and VEGF and VEGFR together as predictive biomarkers may demonstrate improved clinical utility for tailored TNBC therapy.

\section{IL-8}

IL-8 (or CXCL8) is a major CXC motif cytokine encoded by $I L-8$ on chromosome $4 \mathrm{q} 13-\mathrm{q} 21$. IL-8 is produced by TNBC tumors in response to hypoxic conditions and is thought to recruit mesenchymal stem cells (MSCs) to the TNBC location. ${ }^{9}$ MSCs normally reside in the bone marrow and adipose tissue, but when recruited by TNBC, they home to the breast cancer tumor location and create a microenvironment around the tumor hypothesized to increase the stem-cell-like characteristics of the TNBC, ${ }^{29}$ thereby increasing TNBC multidrug resistance (MDR) and metastatic risk. ${ }^{34}$
TNBC often becomes resistant to doxorubicin, a standard anthracycline used in TNBC treatment. ${ }^{40} \mathrm{TNBC}$ resistance to doxorubicin may be due to the ability of IL- 8 to upregulate the BCRP found on the surface of TNBC cells. BCRP is a $72 \mathrm{kDa}$ transmembrane protein responsible for removing doxorubicin from a tumor cell. ${ }^{8,41-43}$ In vitro data suggest that baseline levels of BCRP expression on the cell surface is very high in TNBC, and the expression can be further upregulated in response to drug therapy. ${ }^{8}$ Importantly, BCRP upregulation is transient, lasting only for a few hours after exposing the tumor to doxorubicin ${ }^{8}$ while IL-8 expression can last for several days. ${ }^{44}$ The potential usefulness of IL-8 as a biomarker was demonstrated by an in vitro study by Chen et al, ${ }^{9}$ which demonstrated that IL- 8 increased BCRP expression without affecting the expression of other hallmark efflux transporters correlating with increased TNBC resistance to doxorubicin. IL-8 may serve to protect the TNBC from doxorubicin-induced killing by increasing BCRP levels in TNBC and may function as a surrogate biomarker for BCRP expression in TNBC.

\section{TNBC biomarkers on the cell surface membrane}

Various membrane-bound receptors have the potential function as biomarkers for TNBC as they were shown to increase anti-apoptotic signals in TNBC cell lines; thus, their blockade would be expected to increase tumor death either alone or as part of combination therapy. These biomarkers include EGFR, IGFBP, C-kit, and PD-L1. ${ }^{46-48}$ In this section, each of these membrane-bound candidate biomarkers are described along with the clinical trials in which they were investigated.

\section{EGFR}

The EGFR family consists of four similarly structured RTKs that have important roles in tumor proliferation: EGFR (HER1), HER2, HER3, and HER4. After EGF or a related ligand such as tumor growth factor $\alpha$ binds to the EGFR, the EGFR dimerizes resulting in activation of the EGFR intracellular tyrosine kinase (TK) domain, which in turn recruits additional linker molecules and intracellular TKs. This induces an intracellular signaling cascade that promotes cell proliferation, angiogenesis, metastatic spread, and apoptotic inhibition. Of the four EGFR receptor family members, TNBC most frequently expressed EGFR/HER $1 .{ }^{46}$

Significant evidence shows that EGFR overexpression in TNBC makes TNBC more difficult to treat ${ }^{49}$ and significantly lowers the 10-year survival rate in breast cancer patients. ${ }^{50}$ Although based on preclinical data, anti-EGFR therapy would 
seem to have an application in TNBC, clinical results have so far been disappointing in trials, ${ }^{51}$ and as such, the role of EGFR in TNBC therapy has been a hot topic for debate for the past two decades. ${ }^{49}$ The Asian population might be a special case; however, the studies making these claims do not have an agreed upon mechanism of action. In a genomic analysis of 110 Japanese TNBC patients, 30\% of the TNBC had EGFR overexpression, with 21\% having an EGFR copy number increase. Interestingly, there was no correlation between EGFR expression and EGFR copy number. ${ }^{52} \mathrm{~A}$ later study by Teng et $\mathrm{al}^{53}$ examined 70 Asian TNBC tumors (predominantly Chinese) and found $12 \%$ of the tumors to carry an EGFR mutation. At first glance, the EGFR mutations found in Teng et al's ${ }^{53}$ study appeared to be unique to Asian TNBC as they were not found in any European TNBC study conducted during the same year. ${ }^{54}$ However, like the EGFR copy number changes in the previous study, EGFR mutations did not appear to account for the increased EGFR expression in Asian patients. The biology behind EGFR expression may not be completely explained by genomics. Nevertheless, the EGFR may represent a useful target in Asian patients as EGFR mutations, but not EGFR levels, signal responsiveness to EGFR-targeted therapy in non-small cell lung cancer.

A recent landmark preclinical study by Lim et $\mathrm{al}^{17}$ utilized metabolomics and proteomics to shed light on an EGFR unique mechanism of action in TNBC. Unlike the metabolism in healthy tissue, many tumors metabolize glucose via the aerobic glycolysis pathway. The study by Lim et $\mathrm{ll}^{17}$ examined two vital isozymes that regulate aerobic glycolysis in tumor proliferation: hexokinase 2 (HK2) and pyruvate kinase M2 (PKM2). HK2 catalyzes glucose phosphorylation, the first step in the aerobic glycolysis pathway. EGFR "removes the breaks" from HK2 expression by downregulating miR-148, a microRNA that normally silences HR2 expression. Increased HK2 expression increases glucose utilization. PKM2, an embryonic isozyme, phosphorylates phosphoenolpyruvate into pyruvate, thereby accelerating the last step in aerobic glycolysis. EGFR activity leads to PKM2 phosphorylation at the Tyr 148 residue, forming a slightly less active phosphorylated version (pPKM2) ${ }^{17}$ and thereby slowing down the last step in the aerobic glycolytic pathway.

Increased HK2 activity combined with decreased pyruvate production via pPKM2 creates a "glycolytic jam" where intermediate aerobic glycolytic metabolites accumulate and have the potential to drive the production of nonessential amino acids needed for cellular proliferation. Interestingly, the metabolite fructose 1,6-bisphosphate (F1,6BP) was found to independently alter the phosphorylation of EGFR, thereby creating a positive feedback loop. Because the aerobic glycolytic pathway is active, there is an increase in extracellular lactate production. Lim et $\mathrm{al}^{17}$ found that pPKM2 was positively correlated with increased EGFR expression and increased Ki67 levels, a generalized biomarker for cell proliferation. Because these characteristics were found only in the TNBC lines examined, ${ }^{17}$ extracellular lactate, F1,6BP, and pPKM2 may have roles as predictive biomarkers in EGFR expressing TNBC.

\section{IGFBP}

IGFBPs are a family of six receptors (IGFBP1-IGFBP6) that regulate tumorigenesis through binding to insulin-like growth factors (IGF) both increasing IGF half-life and sequestering IGF. ${ }^{55}$ IGF, in turn, binds and stimulates IGF receptor 1 (IGFR1), which leads to proliferative and antiapoptotic effects through activating the PIK3/AKT pathway. ${ }^{47,56}$ IGFs are secreted by adipocytes as well as cancer cells and have been proposed to increase the risk of breast cancer metastasis. ${ }^{57}$ African-Americans have a higher prevalence of obesity and TNBC risk compared to Caucasians, ${ }^{1,58}$ which may be due to a contribution of the IGFBP/IGF pathway in TNBC.

IGFBP2 is a fetal growth factor overexpressed in neoplastic cells, ${ }^{56}$ especially in HER2-negative breast cancer. ${ }^{59}$ Mechanistic studies examining the role of IGFBP2 in TNBC are limited, but current evidence suggests that IGFBP2 binds both IGF1 and IGF2 and increases the opportunity for IGFs to bind to IGF-1R. ${ }^{47}$

There is conflicting evidence on IGFBP2 as a TNBC marker. Preclinical evidence suggests that IGFBP2 may function as a potential prognostic biomarker. ${ }^{34}$ In addition, IGFBP2 was found to be a predictor of recurrence-free survival (RFS) when measured along with four other proteins in TNBC patients receiving post-neoadjuvant chemotherapy. ${ }^{60}$ However, a report by Hernandez et al $^{61}$ in 2015 disagreed with the findings. Hernandez et al examined the relationship between IGF and IGFBP expression with survival rates in Asian, Pacific Islander, and Caucasian patients and found that increased IGFBP2 expression correlated to a decreased breast cancer survival rate, and the increased IGFBP2 expression varied between racial/ethnic groups. Additionally, this study showed that TNBC was associated with decreased IGF1 and IGFBP2 expression. ${ }^{61}$ The African-Americans, the demographic with the highest TNBC risk, were not tested. IGFBP2 may have utility in combination with other biomarkers as a prognostic biomarker in ethnic populations; however, more evidence for an IGFBP2 correlation with outcomes in the TNBC in the African-American population is needed. 
IGFBP3 has a similar mechanism of action to IGFBP2 by binding to IGF-1 and IGF-2 and increasing its half-life. IGF, in turn, bind to IGF-1R, leading to increased tumor survival. Studies disagree whether IGF-1 and IGF-1R are correlated with the presence of TNBC. ${ }^{35,61}$ Because of the uncertainty of this mechanism, IGFBP3/IGF-1 pathway may be a part of a larger cellular process as IGFBP 3 appears to be independently associated with aggressive TNBC..$^{55}$ Increased IGFBP3 expression appears to increase EGFR expression through sphingosine kinase 1 (SPHK1) activity in TNBC, ${ }^{62,63}$ and as mentioned in the EGFR section, the EGFR can lead to increased cell proliferation, angiogenesis, and tumor metastasis. As such, IGFBP expression may function as a prognostic biomarker, and SPHK1 may function as a PD biomarker.

\section{c-Kit}

c-Kit (also called CD117 and stem cell factor receptor) is an RTK encoded by the 21 exon proto-oncogene, c-Kit, located on chromosome 4q12. c-Kit is found on the surface of hematopoietic stem cells, and after binding to its substrate cytokine, it increases cell survival proliferation and chemotaxis. ${ }^{48}$ The use of $\mathrm{c}-\mathrm{Kit}$ as a TNBC biomarker has been suggested, but is unclear. c-Kit may be expressed in $\sim 25 \%-45 \%$ of TNBC, ${ }^{64,65}$ but studies disagree as to whether c-Kit levels predict the overall survival of TNBC patients..$^{10,66,67} \mathrm{~A}$ Phase II trial examined sunitinib (a targeted agent that inhibits c-Kit as well as multiple other kinases) as monotherapy in patients with advanced TNBC as compared to standard chemotherapeutic regimen and found that sunitinib was not an effective treatment. ${ }^{68}$ Because of the controversial evidence of c-Kit in TNBC, more studies are needed in order to determine its potential usefulness as a TNBC biomarker.

\section{c-Met}

c-Met (also called hepatocyte growth factor receptor [HGFR]) is an RTK that, after binding to its substrate hepatocyte growth factor (HGF), increases cell survival. c-Met is encoded by the proto-oncogene $c$-Met on chromosome 7q21-31, and, while $c$-Met mutation, amplification, or c-Met overexpression leads to increased proliferation, motility, and invasion of cancerous tissue, ${ }^{69}$ increased $c$-Met copy number appears to be the most common origin of c-Met aberrations in TNBC. ${ }^{70,71}$

Contrary to preclinical evidence, recent clinical data suggest that c-Met inhibition may not demonstrate utility as a TNBC treatment option..$^{39,72,73}$ Dieras et al ${ }^{73}$ examined metastatic TNBC treated with the addition a c-Met inhibitor, onartuzumab, alongside bevacizumab or paclitaxel. The addition of the c-Met inhibitor did not improve patients' progression-free survival nor their overall survival. Similarly, Tolaney et $\mathrm{al}^{39}$ examined metastatic TNBC, except the subjects that were treated solely with the oral c-Met inhibitor, tivantinib. Toxicity from the c-Met inhibitor was minimal, but the c-Met inhibitor monotherapy treatment was not efficacious. Although treating TNBC inhibitor does not appear to be as effective as once thought, a meta-analysis conducted by Yan et $\mathrm{al}^{74}$ demonstrated that overexpression of c-Met increases the risk of RFS in TNBC. c-Met may, therefore, function as a prognostic biomarker in TNBC patients.

\section{PD-LI}

Programmed cell death 1 ligand 1 (PD-L1, B7-H1, CD274) is a transmembrane protein encoded by $C D 274$ that functions as a key checkpoint regulator in the immune response. ${ }^{75,76}$ PD-L1 is typically found in B cells, natural killer cells, and vascular endothelial cells and binds the programmed cell death protein 1 (PD-1) found on activated cytotoxic T-cells. PD-L1/PD-1 binding prevents the release of IL-2, T-cell activation, and proliferation, thereby serving as an important regulatory checkpoint preventing excessive adaptive immune responses. ${ }^{75}$

PD-L1 expression on tumor cells appears to be higher in TNBC than non-TNBC ${ }^{75,77}$ and is estimated to occur in $~ 20 \%$ of TNBC..$^{78}$ A recent clinical trial ${ }^{79}$ used pembrolizumab, a high-affinity anti-PD-L1 antibody in metastatic, PD-L1 expressing TNBC patients. The overall survival in patients on pembrolizumab monotherapy was $18.5 \%$, demonstrating the potential role of PD-L1 as a predictive TNBC biomarker in tailoring immune checkpoint therapy.

The exact pathway by which PD-L1 is upregulated in TNBC is not fully understood. A preclinical study by Mittendorf et $\mathrm{al}^{78}$ suggests that PD-L1 expression may be associated with PTEN loss. Mittendorf et al ${ }^{78}$ compared PD-L1 expression in PTEN-knockdown TNBC lines to non-PTEN knockdown lines. As mentioned in the "PIK3CA" section, two downstream targets of PTEN are AKT and mTOR. ${ }^{80}$ When non-PTEN knockdown lines were treated with either AKT inhibitor or mTOR inhibitor, they exhibited inhibited PD-L1 expression while the PTEN knockdown demonstrated increased PD-L1 ${ }^{78}$ As a result, PD-L1 expression may be linked to the activation state of the PIK3CA pathway.

Another potential mechanism by which PD-L1 is upregulated in TNBC is through interferon $\gamma$ (IFN $\gamma$ ), an inflammatory mediator. ${ }^{75,81}$ Soliman et $\mathrm{al}^{75}$ noted two proteins that positively and negatively regulate IFN $\gamma$ expression, STAT1 and interferon regulatory factor 2 binding 2 protein 2 
(IRF2BP2), respectively. The study found that breast cancer cell lines with the highest PD-L1 expression tended to have higher levels of STAT1 and lower levels of IRF2BP2 expression. Although not yet tested clinically, a high STAT1 to low IRFBP2 ratio may identify TNBC that have higher PD-L1 upregulation potential and may function as a surrogate biomarker for response to checkpoint inhibitors.

\section{TNBC biomarkers in the cell cytoplasm}

Majority of the biomarkers in the cytoplasm of TNBC cells have been shown to confer TNBC resistance to drug therapy in interventional studies. ${ }^{82-84}$ These biomarkers include proteins in the PIKCA/AKT/mTOR pathway such as PIK3CA, PTEN, pAKT/pS6/p4E-BP1, and associated metabolites in addition to ALDH1. In this section, these proteins are all detailed along with the clinical trials in which they were investigated.

\section{PIK3CA/AKT/mTOR}

The PIK3CA/AKT/mTOR pathway has gained popularity as a potential route for TNBC resistance to chemotherapy. ${ }^{82,83}$ $P I K 3 C A$, at the top of the pathway, is located in a span of DNA on chromosome $3 q$ that encodes for the $\mathrm{p} 110 \alpha$ catalytic subunit of the phosphoinositide 3-kinase 3A (PIK3CA) among other mediators and is amplified in a significant fraction of TNBC. PIK3A is an upstream catalytic enzyme that, when active, leads to cell growth and proliferation and in particular inhibition of cell death. PIK3CA activating mutations, as well as general dysregulation of the PIK3CA/AKT/ mTOR pathway, are associated with TNBC. ${ }^{85,86}$ PIK3CA phosphorylates phosphatidylinositol 4,5-biphosphate $\left(\mathrm{PIP}_{2}\right)$ to form 3,4,5-triphosphate ( $\left.\mathrm{PIP}_{3}\right)$, which activated multiple proteins containing $\mathrm{PH}$ and other domains that are recruiting to $\mathrm{PIP}_{3}$, thereby leading to the activation of a downstream signaling cascade that mediates the effects of PIK3CA including cell proliferation. $\mathrm{PIP}_{3}$ recruits phosphoinositidedependent kinase 1 (PDK1) and AKT to the cell membrane among other PH domain proteins, and when PDK1 and AKT are in close proximity, PDK1 phosphorylates AKT (pAKT) thereby increasing AKT activity. ${ }^{87}$

\section{pAKT/pS6/p4E-BPI}

pAKT activates mammalian target of rapamycin (mTOR), a key serine/threonine kinase that is vital for TNBC cell survival ${ }^{46}$ and proliferation. ${ }^{88}$ mTOR regulates three important proteins in the PIK3CA/AKT/mTOR pathway: S6, eukaryotic translation initiation factor $4 \mathrm{e}$ binding protein (4E-BP1), and SUV39H1. S6 is a 40S ribosomal protein that regulates translation and is frequently used in determining the downstream activity of an important therapeutic target, the mTOR complex (mTORC1). ${ }^{11}$

Activated mTOR leads to downstream 4E-BP1 phosphorylation ( $\mathrm{p} 4 \mathrm{E}-\mathrm{BP} 1)$, which stimulates cap-independent translation. ${ }^{89}$ Cap-independent translation is a potential mechanism by which large breast tumors stimulate angiogenesis under hypoxic conditions. ${ }^{90}$ Studies on large breast tumors found that 4E-BP1 expression was positively associated with cell survival, demonstrating $\mathrm{p} 4 \mathrm{E}-\mathrm{BP} 1$ 's role as a potential prognostic biomarker. ${ }^{91-93}$ p4E-BP1 can also be used as an indication of the activity of the therapeutic target mTOR complex 1 (mTORC1). When mTORC1 is inhibited, mTORC2 activity increases and vice versa. pS6 and p4E-BP1 have demonstrated usefulness as dual PD biomarkers for determining mTOR pathway activity. ${ }^{11}$

Finding TNBC-specific biomarkers through the mTOR pathway has been challenging, as mTOR expression and activity seem to be similar in TNBC and non-TNBC. ${ }^{94}$ Nascent chromatin capture is a relatively new biochemical process that recently uncovered SUV39H1, a methyltransferase, as a potential protein biomarker. ${ }^{95}$ SUV39H1 modulates DNA expression through histone modification, an epigenetic route of action, which seems to play a major role in homologous recombination (HR), a key DNA damage repair pathway and a determinant of sensitivity to PARP inhibitors and platinum-based chemotherapy. ${ }^{96}$ SUV39H1 may bridge mTOR activity with BRCA1 activity. As mentioned in the "BRCA1" section, many TNBCs have aberrant BRCA1 and BRCA2 function with these proteins playing a critical role in HR in double-strand break repair. ${ }^{97}$ Inhibiting mTOR leads to SUV39H1 suppression, and the decreased SUV39H1 has been correlated to decreased DNA repair in BRCA1mutated TNBC samples, independent of pS6 and p4E-BPT. ${ }^{11}$ SUV39H1 may prove to be useful proteomic/epigenomic PD biomarker in tailored TNBC therapy targeting DNA repair.

\section{PTEN}

PTEN also represents the key negative regulator of PIK3CA/ AKT/mTOR signaling. PTEN is a nine-exon tumor suppressor gene found on chromosome 10q23 that encodes PTEN, a dual acting phosphatase. ${ }^{80}$ PTEN dephosphorylates the 3-phosphoinositide products of PI3Ks, acting as a break for the PI3K/AKT/mTOR pathway, and thus inhibits TNBC metastasis and replication. ${ }^{80}$ PTEN is considered a highpenetrance breast cancer predisposing gene because PTEN mutations found in Cowden's syndrome are associated with and increased lifetime breast cancer incidence. ${ }^{98}$ PTEN SNPs have also been associated with TNBC incidence. ${ }^{99}$ PTEN 
loss, which can occur through multiple mechanisms, has been associated with breast cancer tumor size, grade, reoccurrence, drug resistance, and worse prognosis. ${ }^{100}$

A proteomic study on 76 breast cancer biomarkers examined proteins that could predict RFS in TNBC patients. The study created a risk score (RS) module composed of six proteins. Three were proteins from the PIK3/AKT/mTOR pathway including AKT, S6, and PTEN. The other three proteins were IGFBP, stathmin, a regulator of cell division, and LKB1, a kinase-activating kinase ${ }^{60}$ As mentioned previously in the "PD-L1" section, PTEN loss may be associated with greater PD-L1 expression, ${ }^{78}$ which may help to explain the role of PTEN in TNBC outcomes. ${ }^{99,100}$

\section{Metabolites}

Metabolomics may play an important role in examining the functional consequences of PIK3CA/AKT/mTOR pathway activity. The PIK3CA/AKT/mTOR pathway is a key regulator of glucose uptake. As discussed in the "EGFR" section, tumors frequently have high levels of aerobic glycolysis unlike normal tissues, thereby increasing extracellular lactate concentrations. Moestue et $\mathrm{l}^{15}$ found that inhibition of PI3K/ $\mathrm{mTOR}$ in TNBC decreased lactate production and increased glucose levels. In addition, Chen et $\mathrm{al}^{16}$ found that inhibiting mTOR also leads to EGFR upregulation in TNBC, which has shown to increase lactate production in a recent study by Lin et $\mathrm{al}^{17}$ albeit in the absence of PI3K pathway inhibition. This evidence suggests that lactate/glucose levels may serve as an important metabolomic PD biomarker in monitoring $\mathrm{PI} 3 \mathrm{KCA} / \mathrm{AKT} / \mathrm{mTOR}$ activity, as well as its relationship to EGFR signaling in TNBC-directed therapy.

Choline metabolism may also be selectively important for TNBC. Moestue et al ${ }^{15,101}$ found that PI3K/mTOR inhibition leads to altered choline metabolism in basal-like breast cancer. Glycerophosphocholine (GPC) to phosphocholine (PChO) conversion was significantly higher in aggressive basal-like breast cancer. ${ }^{101}$ Because of the high overlap between TNBC and basal-like breast cancer, ${ }^{50} \mathrm{GPC}$ and PCh may function as prognostic biomarkers in TNBC.

\section{ALDHI}

ALDH1 catalyzes the oxidation of endogenous and exogenous aldehydes into inactive carboxylic acid species. ${ }^{102}$ ALDH1 is a cytoplasmic stem cell-related marker found in a number of breast cancers and is associated with tumor initiating cells. ${ }^{103}$ ALDH1 expression is significantly correlated with tumor grade metastasis ${ }^{104}$ and may be associated with increased resistance to taxane- and epirubicin-based chemotherapy. ${ }^{84}$
ALDH1 may have promise as a TNBC-specific marker. Ohi et al ${ }^{105}$ examined 107 TNBC tumors that express EGFR and cytokeratin 5/6 (this phenotype was described as basalcell TNBC by Kashiwagi et $\mathrm{al}^{10}$ ). The study found that relapse-free survival was lower in ALDH1-positive tumors, suggesting its potential role as a prognostic biomarker in TNBC. Another study examined 147 invasive breast tumors from African patients from Ghana and found an association between the prevalence of ALDH1 expression in TNBC and androgen receptor (AR) expression. ${ }^{106} \mathrm{AR}$ expressing TNBC cell lines are more sensitive to AR antagonists leading to trials exploring the role of AR antagonists in TNBC. ALDH1 is thus a potential predictive biomarker for ARtargeted therapy in $\mathrm{TNBC}^{107}$ as well as a likely prognostic marker.

\section{TNBC biomarkers in the cell nucleus}

A number of nuclear biomarkers including ER and PR have a well-established role as prognostic and predicted biomarkers in breast cancer. The role of nuclear proteins as biomarkers in TNBC is less well developed. A number of nuclear biomarkers including BRCA1/2, GR, and TP53 have been clinically validated as risk factors for cancer development, ${ }^{108}$ tumor survivability, ${ }^{85}$ and tumor proliferation. ${ }^{109}$ In this section, each of these genes and the clinical trials in which they served as biomarkers of disease were described.

\section{$B R C A I$ and BRCA2}

$B R C A 1$ and BRCA2 are protein-expressing spans of DNA found on chromosome 17q21 and 13:12.3, respectively. As noted earlier, these proteins are critical components of the HR DNA repair pathway. Mutations in BRCA1 and BRCA2 have been linked to increased lifetime breast cancer incidence, independent of other breast cancer-related genes. ${ }^{110}$ $B R C A 1$ and BRCA2 are considered a high-penetrance breast cancer-predisposing gene because of the strong correlation between BRCAl aberrant genetic changes (either genomic or epigenomic) and TNBC risk. ${ }^{108}$

Evidence suggests that $B R C A 1$-mutated breast cancer has significant overlap with TNBC. BRCAl-related breast cancers share pathological features with TNBC (a phenotype called "BRCAness") including low or changed expression of ER/PR/HER2, EGFR expression, TP53 mutation, extreme genomic instability from HR deficiency, and a high mitotic index. ${ }^{11,112}$ BRCA1-associated breast cancer also shares two unique metastasis characteristics with TNBC. Although most breast cancer metastasis risks typically correlate with increasing tumor size, there is no apparent association 
between $B R C A 1$-related breast cancer metastasis risk and tumor size, which is also seen in TNBC. In addition, most breast cancer metastasis risk remains constant over time, but in BRCA1-negative breast cancer and TNBC, metastasis risk seems to increase significantly after 3 years, then decline rapidly thereafter. ${ }^{113,114}$

The exact mechanism by which BRCA1 and BRCA2 loss contributes to breast cancer predisposition is still unknown and in particular why individuals with germline mutations are prone to specific subset of tumors such as breast and ovarian cancer. However, the major role is probably due to the defects in HR and gene transcription, and thereby a decreased efficiency in repairing double-strand DNA breaks. ${ }^{108}$ BRCA1 and BRCA2 loss leads to non-HR repair, ${ }^{111}$ thereby increasing genome instability and tumor mutation. ${ }^{97}$ Because $B R C A 1$ and $B R C A 2$ seem to be heavily involved in DNA repair, aberrations in $B R C A 1$ and $B R C A 2$ appear to sensitize TNBC to DNA-damaging platinum agents and PARP inhibitors. A meta-analysis from Chen et $\mathrm{al}^{21}$ examined the risk of remission rate in TNBC using standard neoadjuvant therapy with- or -without carboplatin. The results suggest that carboplatin improves pCR over than other agents used in TNBC treatment.

$B R C A 1$ - and BRCA2-related TNBC is categorized into two groups, familial or sporadic, both of which exhibit the "BRCAness" phenotype. The term "familial" makes the assumption that the cancer occurs due to a germline predisposition aberration. ${ }^{115}$ Clinically, TNBC is classified as familial if the TNBC patient meets the following criteria: the patient has at least three breast and/or ovarian cancer cases in the family, two TNBC cases in close relatives with at least one diagnosed before 50 years old, or two breast cancer cases in the family before 40 years old, Ashekenazi Jewish ancestry, or has ovarian cancer in addition to their TNBC. ${ }^{108}$ Germline BRCA1 and BRCA2 mutations represent the majority of BRCA1- and BRCA2-related TNBC. ${ }^{116-118}$ Majority of familial TNBC may be caused by deleterious germline $B R C A 1$ and $B R C A 2$ mutations ${ }^{18}$ as seen in young TNBC patients ( $<40$ years old) with aggressive $\mathrm{TNBC}^{19}$ and Ashkenazi Jewish TNBC patients. ${ }^{20}$ However, current data suggest that the potential likelihood of an individual with a relatively early onset TNBC having a germline aberration in $B R C A 1$ and $B R C A 2$ is sufficiently high that genetic counseling and genomic testingare warranted.

Only a small proportion of TNBC can be explained by germline aberrations or family history. ${ }^{115}$ Approximately $7 \%$ of breast cancers have somatic mutations in $B R C A 1$ and BRCA2. ${ }^{99,119}$ Epigenetic silencing of BRCA1 but not BRCA2 may contribute to sporadic TNBC. Epigenetic BRCA1 silencing occurs through hypermethylation of $\mathrm{CpG}$ islands in the BRCA1 promotor sequence. ${ }^{23}$ Hsu et $\mathrm{al}^{24}$ examined 139 early stage Taiwanese breast cancer patient tissues and demonstrated an association between hypermethylation of the BRCA1 promoter and TNBC. This idea is reinforced with evidence from a recent study by $\mathrm{Zhu}$ et $\mathrm{al}^{18}$ that found $50 \%$ of sporadic TNBC cases also demonstrated promotor site hypermethylation. ${ }^{120}$ However, there is a conflicting evidence regarding the significance of $\mathrm{CpG}$ island methylation in TNBC. ${ }^{121}$

Epigenetics may be an important factor in tailoring treatment options. One study suggests that a standard anthracycline plus taxane regimen may be more effective in sporadic TNBC with $B R C A 1$ promotor site hypermethylation than those without hypermethylation. ${ }^{26}$ In contrast, another study suggests that the taxane regimens may not be effective in BRCA1 promotor site hypermethylated TNBC but that platinum agents are more effective in treating this subgroup. ${ }^{122}$ Because epigenetic silencing $B C R A 1$ silencing creates a similar BRCA1 expression profile as BRCA1-mutant breast cancer, ${ }^{25}$ epigenetic tests are needed to verify BRCA1 activity and tailor therapy for TNBC. Although mutations in $B R C A 1$ and $B R C A 2$ are clearly associated with prognosis and likely prediction of responsiveness to platinum and PARP inhibitor therapy, it remains unclear whether $B R C A 1$ silencing plays a similar role potentially due to silencing being reversible under therapeutic stress.

\section{GR}

GR is encoded by a nine-exon span of DNA located on 5p31q. ${ }^{123}$ The GR ligand, glucocorticoid (GC), is a proteinbound plasma hormone released from the adrenal cortex during times of stress. Ligand-activated GR translocates to the nucleus where it dimerizes and increases the transcription of GC-inducible genes, ${ }^{124}$ which leads to antiapoptotic activity and resistance to chemotherapy in TNBC. ${ }^{125,126}$

The mechanism by which GR acts has been debated. Preclinical evidence suggests that GR antiproliferative effects are mediated by BRCA1, where BRCA1 activity leads to downstream phosphorylation of the MAPK p38, which, in turn, phosphorylates GR to GR-active and GC independent form (P-Ser211). ${ }^{124}$ However, some studies suggest that GR long-term activity decreases BRCA1 expression while free GR increase BRCA1 expression. ${ }^{127,128}$ More evidence is required for the specifics of this mechanism, but GR and P-Ser211 may be useful proteomic PD biomarkers in TNBC therapy. 


\section{TP53}

TP53 is coded by a gene located on the chromosome $17 \mathrm{p} 13$, encoding the tumor suppression protein $\mathrm{p} 53$. Cellular stress induces p53 expression, which induces cell cycle arrest, apoptosis, DNA repair, and cell-metabolism changes. ${ }^{85}$ TP53 that is mutated in the germline of Li Fraumeni families is a high-penetrance breast cancer disposing gene with mutations in this segment being associated with a high risk of breast cancer and in particular very early onset breast cancer. ${ }^{129}$ Genomic TP53 alterations are prevalent in TNBC tumors ${ }^{99,122}$ with up to $85 \%$ of basal breast cancers having TP53 mutations. ${ }^{45,130}$

There has been a debate over the characteristics of TP53 mutations in TNBC. A study by Kim et $\mathrm{al}^{45}$ found that neither frameshift, nonsense, nor splicing TP53 mutations were associated with breast-specific survival in TNBC. Rather, the study reported that missense DNA binding motif mutations and non-DNA-binding motif mutations were associated with a higher rate for disease relapse. Other studies however propose that loss of TP53 function regardless of the underlying genomic event is associated with worse clinical outcome. Indeed, these studies found no significance in the type of TP53 mutation. ${ }^{122,130}$ Foedermayr et al ${ }^{122}$ found that most of the TP53 mutations in TNBC were localized in the DNA-binding domain. A number of recent studies suggest that decreased TP53 function is associated with worse overall survival in TNBC patients ${ }^{130}$ and increased metastatic risk..$^{85}$ A recent study by Powell et a ${ }^{85}$ suggests that TP53 interacts with the BTG2 promoter, which functions to enhance tumor proliferation. A BTG2 role as a PD biomarker is unclear; however, TP53 mutation may be important as a prognostic biomarker in aggressive TNBC. ${ }^{45}$ The discrepancies between studies on the role of $\mathrm{p} 53$ as a prognostic marker in TNBC may arise from suggestions that the function of the $\mathrm{p} 53$ pathway is abnormal in the majority of basal breast cancer due to aberrations in TP53 as well as other critical members of the pathway. If tumors with TP53 mutations represent only a subset of tumors where the p53 pathway is aberrant, TP53 mutation alone would not be expected to be a powerful biomarker

\section{Conclusion}

Breast cancer is a complex, heterogeneous disease currently categorized by the expression of three predominate receptors, namely ER, PR, and/or HER2, as prognostic and predictive biomarkers. The current recommendations by the ASCO suggest to treat postmenopausal women with ER-expressing metastatic tumors with an aromatase inhibitor such as anastrozole, letrozole, or exemestane, and premenopausal patients with ER-expressing metastatic tumors with a selective ER modulator such as tamoxifen, raloxifene, or toremifene. Likewise, the ASCO suggests to treat HER2-expressing metastatic tumors with trastuzumab, an anti-HER2 monoclonal antibody. ${ }^{4}$ To date, there are no clinically validated biomarkers for TNBC, which has hindered the development $t^{4}$ of tailored therapy for both chemosensitive and refractory TNBC. 5

TNBC biology is a complex interplay of protein-protein, protein-DNA, or other component-component interactions. Indeed, TNBC is the most heterogenous of all types of breast cancer being composed of multiple different subtypes. ${ }^{107}$ Omics technologies provide cutting-edge tools for an in-depth understanding of the molecular landscape of TNBC, where data are extracted from a clinical source, a network between these pathways is inferred, and -omic biomarkers developed through the process of top-down modeling. ${ }^{2,131}$ However, validation of these biomarkers must occur, and stringentclinical criteria met before we can rely on their routine use in the clinical setting. The list provided is an inventory and reference point for promising biomarkers for breakthrough, targeted therapies in TNBC.

\section{Acknowledgments}

We want to thank Dr Gordon Mills at MD Anderson Cancer Center for reviewing this manuscript and sharing his knowledge of biomarkers and TNBC.

\section{Disclosure}

The authors report no conflicts of interest in this work.

\section{References}

1. Siegel R, Ma J, Zou Z, Jemal A. Cancer statistics, 2014. CA Cancer J Clin. 2014;64(1):9-29.

2. Podo F, Buydens LM, Degani H, et al. FEMME Consortium. Triplenegative breast cancer: present challenges and new perspectives. $\mathrm{Mol}$ Oncol. 2010;4(3):209-229.

3. Bender RJ, Mac Gabhann F. Expression of VEGF and semaphorin genes define subgroups of triple negative breast cancer. PLoS One. 2013;8(5):e61788.

4. Van Poznak C, Somerfield MR, Bast RC, et al. Use of biomarkers to guide decisions on systemic therapy for women with metastatic breast cancer: American society of clinical oncology clinical practice guideline. J Oncol Pract. 2015;33(24):2695-2704.

5. Perou CM. Molecular stratification of triple-negative breast cancers Oncologist. 2011;16(Suppl 1):61-70.

6. de Gramont A, Watson S, Ellis LM, Rodón J, Tabernero J, de Gramont A, Hamilton SR. Pragmatic issues in biomarker evaluation for targeted therapies in cancer. Nat Rev Clin Oncol. 2015;12(4):197-212.

7. Lips EH, Michaut M3, Hoogstraat M, et al. Center for Personalized Cancer Treatment. Next generation sequencing of triple negative breast cancer to find predictors for chemotherapy response. Breast Cancer Res. 2015;17(1):134 
8. Dufour R, Daumar P, Mounetou E, et al. BCRP and P-gp relay overexpression in triple negative basal-like breast cancer cell line: a prospective role in resistance to Olaparib. Sci Rep. 2015;5:12670.

9. Chen DR, Lu DY, Lin HY, Yeh WL. Mesenchymal stem cell-induced doxorubicin resistance in triple negative breast cancer. Biomed Res Int. 2014;2014:532161.

10. Kashiwagi S, Yashiro M, Takashima T, et al. c-Kit expression as a prognostic molecular marker in patients with basal-like breast cancer. Br J Surg. 2013;100(4):490-496.

11. Mo W, Liu Q1, Lin CC, et al. mTOR inhibitors suppress homologous recombination repair and synergize with PARP inhibitors via regulating SUV39H1 in BRCA-proficient triple-negative breast cancer. Clin Cancer Res. 2016;22(7):1699-1712.

12. Judes G, Rifaï K, Daures M, Dubois L, Bignon YJ, Penault-Llorca F, Bernard-Gallon D. High-throughput «Omics» technologies: New tools for the study of triple-negative breast cancer. Cancer Lett. 2016.pii: S0304-S3835(16)30137-30139.

13. Claudino WM, Quattrone A, Biganzoli L, Pestrin M, Bertini I, Di Leo A. Metabolomics: available results, current research projects in breast cancer, and future applications. J Clin Oncol. 2007;25(19):2840-2846.

14. Gast MC, Schellens JH, Beijnen JH. Clinical proteomics in breast cancer: a review. Breast Cancer Res Treat. 2009;116(1):17-29.

15. Moestue SA, Dam CG, Gorad SS, et al. Metabolic biomarkers for response to PI3K inhibition in basal-like breast cancer. Breast Cancer Res. 2013;15(1):R16.

16. Chen SM, Guo CL, Shi JJ, et al. HSP90 inhibitor AUY922 abrogates up-regulation of RTKs by mTOR inhibitor AZD8055 and potentiates its antiproliferative activity in human breast cancer. Int $J$ Cancer. 2014;135(10):2462-2474.

17. Lim SO, Li CW, Xia W, et al. EGFR Signaling enhances aerobic glycolysis in triple-negative breast cancer cells to promote tumor growth and immune escape. Cancer Res. 2016;76(5):1284-1296.

18. Zhu X, Shan L, Wang F, et al. Hypermethylation of BRCA1 gene: implication for prognostic biomarker and therapeutic target in sporadic primary triple-negative breast cancer. Breast Cancer Res Treat. 2015;150(3):479-486.

19. Young S, Pilarski RT, Donenberg T, et al. The prevalence of BRCA1 mutations among young women with triple-negative breast cancer. BMC Cancer. 2009;9:86.

20. Nanda R, Schumm LP, Cummings S, et al. Genetic testing in an ethnically diverse cohort of high-risk women: A comparative analysis of brca1 and brca2 mutations in american families of european and african ancestry. JAMA. 2005;294(15):1925-1933.

21. Chen XS, Yuan Y, Garfield DH, Wu JY, Huang O, Shen KW. Both carboplatin and bevacizumab improve pathological complete remission rate in neoadjuvant treatment of triple negative breast cancer: a meta-analysis. PLoS One. 2014;9(9):e108405.

22. Egger G, Liang G, Aparicio A, Jones PA. Epigenetics in human disease and prospects for epigenetic therapy. Nature. 2004;429(6990):457-463.

23. Jaenisch R, Bird A. Epigenetic regulation of gene expression: how the genome integrates intrinsic and environmental signals. Nat Genet. 2003;33 Suppl:245-254.

24. Hsu NC, Huang YF, Yokoyama KK, Chu PY, Chen FM, Hou MF. Methylation of BRCA1 promoter region is associated with unfavorable prognosis in women with early-stage breast cancer. PLoS One. 2013;8(2):e56256.

25. Toffoli S, Bar I, Abdel-Sater F, et al. Identification by array comparative genomic hybridization of a new amplicon on chromosome $17 \mathrm{q}$ highly recurrent in BRCA1 mutated triple negative breast cancer. Breast Cancer Res. 2014;16(6):466.

26. XuY, Diao L, Chen Y, et al. Promoter methylation of BRCA1 in triplenegative breast cancer predicts sensitivity to adjuvant chemotherapy. Ann Oncol. 2013;24(6):1498-1505.

27. Saini KS, Saini ML, Marbaix E. Biobanking in the era of precision oncology. Indian J Med Paediatr Oncol. 2015;36(1):1-2.

28. Wagner PD, Srivastava S. New paradigms in translational science research in cancer biomarkers. Transl Res. 2012;159(4):343-353.
29. Houthuijzen JM, Daenen LGM, Roodhart JML, Voest EE. The role of mesenchymal stem cells in anti-cancer drug resistance and tumour progression. Br J Cancer. 2012;106(12):1901-1906.

30. Xin Y, Li J, Wu J, et al. Pharmacokinetic and pharmacodynamic analysis of circulating biomarkers of anti-NRP1, a novel antiangiogenesis agent, in two phase I trials in patients with advanced solid tumors. Clin Cancer Res. 2012;18(21):6040-6048.

31. Achen MG, Stacker SA. The vascular endothelial growth factor family; proteins which guide the development of the vasculature. Int J Exp Pathol. 1998;79(5):255-265.

32. Nishida N, Yano H, Nishida T, Kamura T, Kojiro M. Angiogenesis in cancer. Vasc Health Risk Manag. 2006;2(3):213-219.

33. Ning Q, Liu C, Hou L, et al. Vascular endothelial growth factor receptor-1 activation promotes migration and invasion of breast cancer cells through epithelial-mesenchymal transition. PLoS One. 2013;8(6):e65217.

34. Roberti MP, Arriaga JM, Bianchini M, et al. Protein expression changes during human triple negative breast cancer cell line progression to lymph node metastasis in a xenografted model in nude mice. Cancer Biol Ther. 2012;13(11):1123-1140.

35. Bahhnassy A, Mohanad M, Shaarawy S, et al. Transforming growth factor- $\beta$, insulin-like growth factor I/insulin-like growth factor I receptor and vascular endothelial growth factor-A: prognostic and predictive markers in triple-negative and non-triple-negative breast cancer. $\mathrm{Mol}$ Med Rep. 2015;12(1):851-864.

36. Ghosh S, Sullivan CA, Zerkowski MP, et al. High levels of vascular endothelial growth factor and its receptors (VEGFR-1, VEGFR-2, neuropilin-1) are associated with worse outcome in breast cancer. Human Pathol. 2008;39(12):1835-1843.

37. Taha FM, Zeeneldin AA, Helal AM, et al. Prognostic value of serum vascular endothelial growth factor in Egyptian females with metastatic triple negative breast cancer. Clin Biochem. 2009;42(13-14):1420-1426.

38. Bear HD, Tang G, Rastogi P, et al. Bevacizumab added to neoadjuvant chemotherapy for breast cancer. NEngl J Med. 2012;366(4):310-320.

39. Tolaney SM, Boucher Y, Duda DG, et al. Role of vascular density and normalization in response to neoadjuvant bevacizumab and chemotherapy in breast cancer patients. Proc Natl Acad Sci U S A. 2015;112(46):14325-14330.

40. André F, Zielinski CC. Optimal strategies for the treatment of metastatic triple-negative breast cancer with currently approved agents. Ann Oncol. 2012;23(Suppl 6):vi46-vi51.

41. Natarajan K, Xie Y, Baer MR, Ross DD. Role of breast cancer resistance protein (BCRP/ABCG2) in cancer drug resistance. Biochem Pharmacol. 2012;83(8):1084-1103.

42. Finn RS, Bengala C, Ibrahim N, et al. Dasatinib as a single agent in triple-negative breast cancer: results of an open-label phase 2 study. Clin Cancer Res. 2011;17(21):6905-6913.

43. Komeili-Movahhed T, Fouladdel S, Barzegar E, et al. PI3K/Akt inhibition and down-regulation of BCRP re-sensitize MCF7 breast cancer cell line to mitoxantrone chemotherapy. Iran J Basic Med Sci. 2015;18(5):472-477.

44. Villarete LH, Remick DG. Transcriptional and post-transcriptional regulation of interleukin-8. Am J Pathol. 1996;149(5):1685-1693.

45. Montero JC, Esparis-Ogando A, Re-Louhau MF, et al. Active kinase profiling, genetic and pharmacological data define mTOR as an important common target in triple-negative breast cancer. Oncogene. 2014;33(2):148-156.

46. Baxi SM, Tan W, Murphy ST, Smeal T, Yin MJ. Targeting 3-phosphoinoside - dependent kinase-1 to inhibit insulin-like growth factor-I induced AKT and p70 S6 kinase activation in breast cancer cells. PLoS One. 2012;7(10):e48402.

47. Edling CE, Hallberg B. c-Kit - a hematopoietic cell essential receptor tyrosine kinase. Int J Biochem Cell Biol. 2007;39(11):1995-1998.

48. Nogi H, Kobayashi T, Suzuki M, et al. EGFR as paradoxical predictor of chemosensitivity and outcome among triple-negative breast cancer. Oncol Rep. 2009;21(2):413-417. 
49. Cheang MC, Voduc D, Bajdik C, et al. Basal-like breast cancer defined by five biomarkers has superior prognostic value than triple-negative phenotype. Clin Cancer Res. 2008;14(5):1368-1376.

50. Carey LA, Rugo HS, Marcom PK, et al. TBCRC 001: randomized phase II study of cetuximab in combination with carboplatin in stage IV triple-negative breast cancer. J Clin Oncol. 2012;30(21):2615-2623.

51. Toyama T, Yamashita H, Kondo N, et al. Frequently increased epidermal growth factor receptor (EGFR) copy numbers and decreased BRCA1 mRNA expression in Japanese triple-negative breast cancers. $B M C$ Cancer. 2008;8:309.

52. Teng YH, Tan WJ, Thike AA, et al. Mutations in the epidermal growth factor receptor (EGFR) gene in triple negative breast cancer: possible implications for targeted therapy. Breast Cancer Res. 2011;13(2):R35.

53. Jacot W, Lopez-Crapez E, Thezenas S, et al. Lack of EGFR-activating mutations in European patients with triple-negative breast cancer could emphasise geographic and ethnic variations in breast cancer mutation profiles. Breast Cancer Res. 2011;13(6):1-9.

54. Marzec KA, Baxter RC, Martin JL. Targeting insulin-like growth factor binding protein-3 signaling in triple-negative breast cancer. BioMed Res Int. 2015;2015:638526.

55. Zha J, Lackner MR. Targeting the insulin-like growth factor receptor-1R pathway for cancer therapy. Clin Cancer Res. 2010;16(9): 2512-2517.

56. Wang C, Gao C, Meng K, Qiao H, Wang Y. Human adipocytes stimulate invasion of breast cancer MCF-7 cells by secreting IGFBP-2. PLOS One. 2015;10(3):e0119348.

57. Rose DP, Haffner SM, Baillargeon J. Adiposity, the metabolic syndrome, and breast cancer in African-American and white American women. Endocr Rev. 2007;28(7):763-777.

58. Mountzios G, Aivazi D, Kostopoulos I, et al. Differential expression of the insulin-like growth factor receptor among early breast cancer subtypes. PLoS One. 2014;9(3):e91407.

59. Sohn J, Do KA, Liu S, et al. Functional proteomics characterization of residual triple-negative breast cancer after standard neoadjuvant chemotherapy. Ann Oncol. 2013;24(10):2522-2526.

60. Hernandez BY, Wilkens LR, Le Marchand L, Horio D, Chong CD, Loo LW. Differences in IGF-axis protein expression and survival among multiethnic breast cancer patients. Cancer Med. 2015;4(3): 354-362.

61. Martin JL, de Silva HC, Lin MZ, Scott CD, Baxter RC. Inhibition of insulin-like growth factor-binding protein-3 signaling through sphingosine kinase-1 sensitizes triple-negative breast cancer cells to EGF receptor blockade. Mol Cancer Ther. 2014;13(2):316-328.

62. Li J, Song Z, Wang Y, et al. Overexpression of SphK1 enhances cell proliferation and invasion in triple-negative breast cancer via the PI3K/ AKT signaling pathway. Tumour Biol. 2016;37(8):10587-10593.

63. Thike AA, Cheok PY, Jara-Lazaro AR, Tan B, Tan P, Tan PH. Triplenegative breast cancer: clinicopathological characteristics and relationship with basal-like breast cancer. Mod Pathol. 2010;23(1):123-133.

64. Zhu Y, Wang Y, Guan B, et al. C-kit and PDGFRA gene mutations in triplenegative breast cancer. Int J Clin Exp Pathol. 2014;7(7): $4280-4285$

65. Johansson I, Aaltonen KE, Ebbesson A, et al. Increased gene copy number of KIT and VEGFR2 at $4 \mathrm{q} 12$ in primary breast cancer is related to an aggressive phenotype and impaired prognosis. Genes Chromosomes Cancer. 2012;51(4):375-383.

66. Jansson S, Bendahl Pä O, Grabau DA, et al. The three receptor tyrosine kinases c-KIT, VEGFR2 and PDGFR $\alpha$, closely spaced at 4q12, show increased protein expression in triple-negative breast cancer. PLoS One. 2014;9(7):e102176.

67. Curigliano G, Pivot X, Cortes J, et al. Randomized phase II study of sunitinib versus standard of care for patients with previously treated advanced triple-negative breast cancer. Breast. 2013;22(5):650-656.

68. Organ SL, Tsao MS. An overview of the c-MET signaling pathway. Ther Adv Med Oncol. 2011;3(1 Suppl):S7-S19.

69. Hsu YH, Yao J, Chan LC, et al. Definition of PKC-alpha, CDK6, and MET as therapeutic targets in triple-negative breast cancer. Cancer Res. 2014;74(17):4822-4835.
70. Gonzalez-Angulo AM, Chen H, Karuturi MS, et al. Frequency of mesenchymal-epithelial transition factor gene (MET) and the catalytic subunit of phosphoinositide-3-kinase (PIK3CA) copy number elevation and correlation with outcome in patients with early stage breast cancer. Cancer. 2013;119(1):7-15.

71. Yi YW, You K, Bae EJ, Kwak SJ, Seong YS, Bae I. Dual inhibition of EGFR and MET induces synthetic lethality in triple-negative breast cancer cells through downregulation of ribosomal protein S6. Int J Oncol. 2015;47(1):122-132.

72. Dieras V, Campone M, Yardley DA, et al. Randomized, phase II, placebo-controlled trial of onartuzumab and/or bevacizumab in combination with weekly paclitaxel in patients with metastatic triple-negative breast cancer. Ann Oncol. 2015;26(9):1904-1910.

73. Tolaney SM, Tan S, Guo H, et al. Phase II study of tivantinib (ARQ 197 ) in patients with metastatic triple-negative breast cancer. Invest New Drugs. 2015;33(5):1108-1114.

74. Yan S, Jiao X, Zou H, Li K. Prognostic significance of c-Met in breast cancer: a meta-analysis of 6010 cases. Diagn Pathol. 2015;10:62.

75. Soliman H, Khalil F, Antonia S. PD-L1 expression is increased in a subset of basal type breast cancer cells. PLoS One. 2014;9(2):e88557.

76. Muenst S, Schaerli AR, Gao F, et al. Expression of programmed death ligand 1 (PD-L1) is associated with poor prognosis in human breast cancer. Breast Cancer Res Treat. 2014;146(1):15-24.

77. Gatalica Z, Snyder C, Maney T, et al. Programmed cell death 1 (PD1 ) and its ligand (PD-L1) in common cancers and their correlation with molecular cancer type. Cancer Epidemiol Biomarkers Prev. 2014;23(12):2965-2970.

78. Mittendorf EA, Philips AV, Meric-Bernstam F, et al. PD-L1 Expression in triple negative breast cancer. Cancer Immunol Res. 2014;2(4): 361-370.

79. Nanda R, Chow LQ, Dees EC, et al. Pembrolizumab in patients with advanced triple-negative breast cancer: phase Ib KEYNOTE-012 study. $J$ Clin Oncol. 2016;34(21):2460-2467.

80. Hollander MC, Blumenthal GM, Dennis PA. PTEN loss in the continuum of common cancers, rare syndromes and mouse models. Nat Rev Cancer. 2011;11(4):289-301.

81. Keir ME, Butte MJ, Freeman GJ, Sharpe AH. PD-1 and its ligands in tolerance and immunity. Annu Rev Immunol. 2008;26:677-704.

82. Pande M, Bondy ML, Do KA, et al. Association between germline single nucleotide polymorphisms in the PI3K-AKT-mTOR pathway, obesity, and breast cancer disease-free survival. Breast Cancer Res Treat. 2014;147(2):381-387.

83. Miller TW, Balko JM, Arteaga CL. Phosphatidylinositol 3-kinase and antiestrogen resistance in breast cancer. J Clin Oncol. 2011;29(33): 4452-4461.

84. Tanei T, Morimoto K, Shimazu K, et al. Association of breast cancer stem cells identified by aldehyde dehydrogenase 1 expression with resistance to sequential paclitaxel and epirubicin-based chemotherapy for breast cancers. Clin Cancer Res. 2009;15(12):4234-4241.

85. Powell E, Shao J, Yuan Y, et al. p53 deficiency linked to B cell translocation gene 2 (BTG2) loss enhances metastatic potential by promoting tumor growth in primary and metastatic sites in patient-derived xenograft (PDX) models of triple-negative breast cancer. Breast Cancer Res. 2016;18(1):13.

86. Shah SP, Roth A, Goya R, et al. The clonal and mutational evolution spectrum of primary triple negative breast cancers. Nature. 2012;486(7403):395-399.

87. Cantley LC. The Phosphoinositide 3-kinase pathway. Science. 2002;296(5573):1655-1657.

88. Yamnik RL, Digilova A, Davis DC, Brodt ZN, Murphy CJ, Holz MK S6 kinase 1 regulates estrogen receptor alpha in control of breast cancer cell proliferation. J Biol Chem. 2009;284(10):6361-6369.

89. Gingras AC, Gygi SP, Raught B, et al. Regulation of 4E-BP1 phosphorylation: a novel two-step mechanism. Genes Dev. 1999;13(11): 1422-1437.

90. Braunstein S, Karpisheva K, Pola C, et al. A hypoxia-controlled capdependent to cap-independent translation switch in breast cancer. Mol Cell. 2007;28(3):501-512. 
91. Zhou X, Tan M, Stone Hawthorne V, et al. Activation of the Akt/mammalian target of rapamycin/4E-BP1 pathway by ErbB2 overexpression predicts tumor progression in breast cancers. Clin Cancer Res. 2004;10(20):6779-6788.

92. Shrivastava S, Kulkarni P, Thummuri D, et al. Piperlongumine, an alkaloid causes inhibition of PI3 K/Akt/mTOR signaling axis to induce caspase-dependent apoptosis in human triple-negative breast cancer cells. Apoptosis. 2014;19(7):1148-1164.

93. De P, Sun Y, Carlson JH, Friedman LS, Leyland-Jones BR, Dey N. Doubling down on the PI3K-AKT-mTOR pathway enhances the antitumor efficacy of PARP inhibitor in triple negative breast cancer model beyond BRCA-ness. Neoplasia. 2014;16(1):43-72.

94. Walsh S, Flanagan L, Quinn C, et al. mTOR in breast cancer: differential expression in triple-negative and non-triple-negative tumors. Breast. 2012;21(2):178-182.

95. Alabert C. Chromatin dynamics during DNA replication and uncharacterized replication factors determined by nascent chromatin capture (NCC) proteomics. Nat Cell Biol. 2014;16(3):281-293.

96. Alagoz M, Katsuki Y, Ogiwara H, et al. SETDB1, HP1 and SUV39 promote repositioning of 53BP1 to extend resection during homologous recombination in G2 cells. Nucleic Acids Research. 2015;43(16):7931-7944.

97. Choi JD, Park MA, Lee JS. Suppression and recovery of BRCA1mediated transcription by HP1gamma via modulation of promoter occupancy. Nucleic Acids Res. 2012;40(22):11321-11338.

98. Tan MH, Mester JL, Ngeow J, Rybicki LA, Orloff MS, Eng C. Lifetime cancer risks in individuals with germline PTEN mutations. Clin Cancer Res. 2012;18(2):400-407.

99. Hicks C, Kumar R, Pannuti A, et al. An integrative genomics approach for associating GWAS information with triple-negative breast cancer. Cancer Inform. 2013;12:1-20.

100. Beg S, Siraj AK, Prabhakaran S, et al. Loss of PTEN expression is associated with aggressive behavior and poor prognosis in Middle Eastern triple-negative breast cancer. Breast Cancer Res Treat. 2015;151(3):541-553.

101. Grinde MT, Skrbo N, Moestue SA, et al. Interplay of choline metabolites and genes in patient-derived breast cancer xenografts. Breast Cancer Res. 2014;16(1):R5.

102. Tomita H, Tanaka K, Tanaka T, Hara A. Aldehyde dehydrogenase 1A1 in stem cells and cancer. Oncotarget. 2016;7(10):11018-11032.

103. Kim SJ, Kim YS, Jang ED, Seo KJ, Kim JS. Prognostic impact and clinicopathological correlation of CD133 and ALDH1 expression in invasive breast cancer. J Breast Cancer. 2015;18(4): 347-355.

104. Marcato P, Dean CA, Pan D, et al. Aldehyde dehydrogenase activity of breast cancer stem cells is primarily due to isoform ALDH1A3 and its expression is predictive of metastasis. Stem Cells. 2011;29(1): 32-45.

105. Ohi Y, Umekita Y, Yoshioka T, et al. Aldehyde dehydrogenase 1 expression predicts poor prognosis in triple-negative breast cancer. Histopathology. 2011;59(4):776-780.

106. Proctor E, Kidwell KM, Jiagge E, et al. Characterizing breast cancer in a population with increased prevalence of triple-negative breast cancer: androgen receptor and ALDH1 expression in ghanaian women. Ann Surg Oncol. 2015;22(12):3831-3835.

107. Lehmann BD, Bauer JA, Chen X, Sanders ME, Chakravarthy AB, Shyr Y, Pietenpol JA. Identification of human triple-negative breast cancer subtypes and preclinical models for selection of targeted therapies. J Clin Invest. 2011;121(7):2750-2767.

108. Shiovitz S, Korde LA. Genetics of breast cancer: a topic in evolution. Ann Oncol. 2015;26(7):1291-1299.

109. Urruticoechea A, Smith IE, Dowsett M. Proliferation marker Ki-67 in early breast cancer. J Clin Oncol. 2005;23(28):7212-7220.

110. Tung N, Lin NU, Kidd J, et al. Frequency of germline mutations in 25 cancer susceptibility genes in a sequential series of patients with breast cancer. J Clin Oncol. 2016;34(13):1460-1468.

111. Turner N, Tutt A, Ashworth A. Hallmarks of 'BRCAness' in sporadic cancers. Nat Rev Cancer. 2004;4(10):814-819.
112. Lee LJ, Alexander B, Schnitt SJ, Comander A, Gallagher B, Garber JE, Tung N. Clinical outcome of triple negative breast cancer in BRCA1 mutation carriers and non-carriers. Cancer. 2011;117(14):3093-3100.

113. Dent R, Trudeau M, Pritchard KI, et al. Triple-negative breast cancer: clinical features and patterns of recurrence. Clin Cancer Res. 2007;13(15):4429-4434

114. Foulkes WD, Metcalfe K, Hanna W, et al. Disruption of the expected positive correlation between breast tumor size and lymph node status in BRCA1-related breast carcinoma. Cancer. 2003;98(8):1569-1577.

115. Anderson DE. Familial versus sporadic breast cancer. Cancer. 1992;70(6 Suppl):1740-1746.

116. Atchley DP, Albarracin CT, Lopez A, et al. Clinical and pathologic characteristics of patients with BRCA-positive and BRCA-negative breast cancer. J Clin Oncol. 2008;26(26):4282-4288.

117. Musolino A, Bella MA, Bortesi B, et al. BRCA mutations, molecular markers, and clinical variables in early-onset breast cancer: a population-based study. Breast. 2007;16(3):280-292.

118. Stefansson OA, Jonasson JG, Johannsson OT, Olafsdottir K, Steinarsdottir M, Valgeirsdottir S, Eyfjord JE. Genomic profiling of breast tumours in relation to BRCA abnormalities and phenotypes. Breast Cancer Res. 2009;11(4):R47.

119. Zugazagoitia J, Pérez-Segura P, Manzano A, et al. Limited family structure and triple-negative breast cancer (TNBC) subtype as predictors of BRCA mutations in a genetic counseling cohort of early-onset sporadic breast cancers. Breast Cancer Res Treat. 2014;148(2):415-421.

120. Stefansson OA, Jonasson JG, Olafsdottir K, et al. CpG island hypermethylation of BRCA1 and loss of $\mathrm{pRb}$ as co-occurring events in basal/triple-negative breast cancer. Epigenetics. 2011;6(5):638-649.

121. Branham MT, Marzese DM, Laurito SR, et al. Methylation profile of triple-negative breast carcinomas. Oncogenesis. 2012;1(7):e17.

122. Foedermayr M, Sebesta M, Rudas M, et al. BRCA-1 methylation and TP53 mutation in triple-negative breast cancer patients without pathological complete response to taxane-based neoadjuvant chemotherapy. Cancer Chemother Pharmacol. 2014;73(4):771-778.

123. Mitre-Aguilar IB, Cabrera-Quintero AJ, Zentella-Dehesa A. Genomic and non-genomic effects of glucocorticoids: implications for breast cancer. Int J Clin Exp Pathol. 2015;8(1):1-10.

124. Vilasco M, Communal L, Hugon-Rodin J, et al. Loss of glucocorticoid receptor activation is a hallmark of BRCA1-mutated breast tissue. Breast Cancer Res Treat. 2013;142(2):283-296.

125. Reeder A, Attar M, Nazario L, et al. Stress hormones reduce the efficacy of paclitaxel in triple negative breast cancer through induction of DNA damage. Br J Cancer. 2015;112(9):1461-1470.

126. Skor MN, Wonder EL, Kocherginsky M, Goyal A, Hall BA, Cai Y, Conzen SD. Glucocorticoid receptor antagonism as a novel therapy for triple-negative breast cancer. Clin Cancer Res. 2013;19(22):6163-6172.

127. Antonova L, Mueller CR. Hydrocortisone down-regulates the tumor suppressor gene BRCA1 in mammary cells: a possible molecular link between stress and breast cancer. Genes Chromosomes Cancer. 2008;47(4):341-352.

128. Ritter HD, Antonova L, Mueller CR. The unliganded glucocorticoid receptor positively regulates the tumor suppressor gene BRCA1 through GABP beta. Mol Cancer Res. 2012;10(4):558-569.

129. Birch JM, Alston RD, McNally RJ, et al. Relative frequency and morphology of cancers in carriers of germline TP53 mutations. Oncogene. 2001;20(34):4621-4628.

130. Kim Y, Kim J, Lee HD, Jeong J, Lee W, Lee KA. Spectrum of EGFR gene copy number changes and KRAS gene mutation status in korean triple negative breast cancer patients. PLoS One. 2013;8(10):e79014.

131. Kim JY, Park K, Jung HH, et al. Association between mutation and expression of TP53 as a potential prognostic marker of triple-negative breast cancer. Cancer Res Treat. Epub 2016 Feb 18.

132. Çakır T, Khatibipour MJ. Metabolic network discovery by top-down and bottom-up approaches and paths for reconciliation. Front Bioeng Biotechnol. 2014;2:62.

133. Dean SJ, Perks CM, Holly JM, et al. Loss of PTEN expression is associated with IGFBP2 expression, younger age, and late stage in triple-negative breast cancer. Am J Clin Pathol. 2014;141(3):323-333. 
Breast Cancer - Targets and Therapy is an international, peerreviewed open access journal focusing on breast cancer research, identification of therapeutic targets and the optimal use of preventative and integrated treatment interventions to achieve improved outcomes, enhanced survival and quality of life for the cancer patient
The manuscript management system is completely online and includes a very quick and fair peer-review system, which is all easy to use. Visit http://www.dovepress.com/testimonials.php to read real quotes from published authors.

Submit your manuscript here: https:/www.dovepress.com/breast-cancer---targets-and-therapy-journal 